\title{
RANCANG BANGUN SISTEM INFORMASI AKUNTANSI DANA SUBSIDI
}

\author{
Ratna Sri Hayati \\ Universitas Potensi Utama \\ Jl. K.L. Yos Sudarso Km. 6.5 No.3-A, Tanjung Mulia - Medan \\ Email : ratnayach@gmail.com
}

\begin{abstract}
Abstrak
Sebagai suatu sistem informasi, akuntansi melaksanakan pengumpulan dan pengolahan data keuangan sekolah untuk kemudian hari mengkomunikasikannya kepada berbagai pihak yang berkepentingan agar dapat digunakan sebagai alat bantu dalam mengambil keputusan. Sehubungan dengan itu, diperlukan suatu sistem akuntansi yang handal sehingga mampu menyajikan informasi tentang posisi keuangan, kinerja dan arus dana dari suatu unit ekonomi kepada para pengambil keputusan. Program pemberian dana subsidi bertujuan untuk memberikan bekal kemampuan penguasaan kompetensi mengenai salah satu jenis keterampilan yang sesuai dengan kondisi sosial dan ekonomi setempat, agar terlaksananya program pemerintah wajib belajar 9 tahun. Pada penelitian ini, penulis merancang sistem informasi akuntansi dana subsidi dengan menggunakan database sebagai tempat penyimpanan sistem agar dapat mempermudah proses pengolahan dana subsidi terhadap penerimaan, pengeluaran dan laporan dana subsidi perperiodik. Sistem yang dirancang dapat memberikan solusi pengolahan dana subsidi dan membantu memberikan laporan keuangan dana subsidi dengan cepat dan akurat.
\end{abstract}

Kata kunci: Sistem Informasi, Akuntansi, Subsidi

\begin{abstract}
As an information system, accounting implement the collection and processing of financial data for later school communicate to various stakeholders in order to be used as a tool in making decisions. In connection with that, we need a reliable accounting system so as to provide information about the financial position, performance and financial flows of an economic unit to decision makers. Subsidy grant program aims to provide the capability to master competencies provision regarding one kind of skills that correspond to local social and economic conditions, so that the implementation of the government program of compulsory nine years. In this study, the authors designed a subsidy fund accounting information system by using the database as a storage system in order to facilitate the processing of subsidy funds to the receipt, expenditure and reporting perperiodik subsidy fund. The system is designed to provide subsidy funds processing solution and helps provide financial statements subsidy funds quickly and accurately.
\end{abstract}

Keywords: Accounting, Information Systems, Subsidies

\section{PENDAHULUAN}

Untuk mencegah terjadinya anak-anak putus sekolah dan tidak memiliki suatu keterampilan khusus, pemerintah meminta sekolah-sekolah agar segera mengusulkan penerimaan subsidi dan mengolah dana subsidi tersebut sebaik mungkin sesuai ketentuan yang telah ditetapkan agar dapat mengembangkan potensi yang dimiliki anak didik dengan memberikan latihan khusus pendidikan keterampilan. Dengan diberikannya bekal keterampilan yang bermanfaat bagi tamatan SMP yang tidak melanjutkan pelajaran ke jenjang yang lebih tinggi, mereka dapat lebih siap untuk terjun ke masyarakat. Dengan demikian, peran akuntansi menjadi penting untuk mengolah dan memberikan informasi keuangan bagi Kepala Sekolah, Bendahara 
dan Tata Usaha terhadap pengolahan dana subsidi yang akan dipergunakan sebagai dasar dalam perencanaan dan pengendalian, dan akhirnya pengambilan keputusan manajemen[1].

Sebagai suatu sistem informasi akuntansi melaksanakan pengumpulan dan pengolahan data keuangan sekolah untuk kemudian hari mengkomunikasikannya kepada berbagai pihak yang berkepentingan agar dapat digunakan sebagai alat bantu dalam mengambil keputusan[2]. Sehubungan dengan itu, diperlukan suatu sistem akuntansi yang handal dan tidak menyesatkan, sehingga mampu menyajikan informasi tentang posisi keuangan, kinerja dan arus dana dari suatu unit ekonomi kepada para pengambil keputusan. Artinya setiap divisi keuangan melaporkan hasil operasinya selama periode tertentu.

Subsidi adalah bantuan berupa dana yang diberikan pemerintah kepada instansi pemerintah yang membutuhkan bantuan untuk mengelola Program Pendidikan Keterampilan (PPK), dengan syarat dan ketentuan yang telah ditetapkan. Untuk memperoleh dana subsidi yang dimaksud, maka pemohon harus terlebih dahulu mengajukan Proposal Program Pendidikan Keterampilan ke Direktorat Pembinaan Sekolah ( Depdiknas, No. 0019/C3/PK/2010 : 1 ).[5]

Subsidi Keterampilan adalah program pemberian dana subsidi keterampilan yang bertujuan untuk memberikan bekal kemampuan penguasaan kompetensi mengenai salah satu jenis keterampilan yang sesuai dengan kondisi sosial dan ekonomi setempat, agar terlaksananya program pemerintah wajib belajar 9 tahun dengan mempertahankan mutu dan hasil pendidikan yang akan diperoleh ( Depdiknas, No.0019/C3/PK/2010 : 2 ).

Proporsi pemanfaatan dana subsidi keterampilan adalah :

1. Pengadaan Peralatan

a. Pelaksanaan PPK dengan jenis keterampilan yang baru, alokasi dana subsidinya maksimum sebesar 50\% dari dana yang disediakan.

b. Pelaksanaan PPK sebagai lanjutan, alokasi dana subsidinya maksimum sebesar 50\% dari dana yang disediakan.

2. Pelaksanaan Kegiatan

a. Pengadaan Bahan Praktik

Alokasi dana subsidi untuk pengadaan bahan praktik maksimum sebesar $80 \%$ dari dana yang disediakan.

b. Pendamping Pelaksanaan Program Pendidikan Keterampilan

Alokasi dana subsidi untuk pengadaan bahan praktik maksimum sebesar $15 \%$ dari dana yang disediakan.

3. Manajemen

Alokasi dana subsidi untuk manajemen maksimum sebesar $20 \%$ dari dana yang disediakan, yang dipergunakan untuk :

a. Pemeliharaan dan perawatan bahan praktik.

b. Pengelolaan PPK

c. Biaya yang tidak terduga

Berdasarkan latar belakang penelitian diatas, maka dibutuhkan pengelolaan sistem informasi akuntansi dana subsidi yang baik untuk memberikan solusi laporan keuangan bagi sekolah yang menerima dana subsidi. Pada penelitian ini, penulis merancang sistem informasi akuntansi dana subsidi dengan menggunakan database sebagai tempat penyimpanan sistem agar dapat mempermudah proses pengolahan dana subsidi terhadap penerimaan[4], pengeluaran dan laporan dana subsidi perperiodik.

\section{Metode Penelitian}

ANALISA

Dalam penelitian ini penulis lebih membahas analisa sistem informasi akuntansi dana subsidi di instansi pendidikan (sekolah). Pada penelitian sebelumnya sistem informasi yang dibangun adalah sistem informasi penerimaan dana subsidi yang dirancang untuk menghasilkan laporan dana subsidi di suatu sekolah. Pada penelitian ini, penulis menggunakan 3 entitas yaitu Pendana, Tata Usaha Sekolah dan Kepala Sekolah. Hasil penelitian ini adalah sistem informasi akuntansi yang dikembangkan dapat mempermudah proses pengolahan dana subsidi terhadap 
penerimaan, pengeluaran dan laporan dana subsidi perperiodik. Namun penulis tidak membahas masalah analisa sistem, analisa sistem sendiri sangat dibutuhkan karena analisa sistem dapat mengidentifikasi masalah atau hambatan yang terjadi dan kebutuhan yang diharapkan sehingga muncul perbaikan hingga sistem menjadi sempurna.

\section{SISTEM INFORMASI}

Sistem informasi adalah berupa suatu sistem di dalam suatu organisasi yang mempertemukan kebutuhan pengolahan data transaksi harian yangmendukung operasi yang bersifat manajerial dengan kegiatan strategi suatu organisasi untuk dapat menyediakan kepada pihak luar tertentu dengan laporan-laporan yang diperlukan (Tata Sutabri; 2005).

\section{AKUNTANSI}

Akuntansi adalah pencatatan, penggolongan, peringkasan yang tepat dan dinyatakan dalam uang, transaksi - transaksi dan kejadian - kejadian yang bersifat financial dan penafsiran dari hasil - hasilnya. Dengan kata lain, Akuntansi adalah suatu laporan posisi keuangan mulai dari proses pencatatan sampai kepada pertanggungjawaban (laporan) kepada pihak yang terkait(Euis Ristanti ; 2005).

\section{METODE PENELITIAN}

Metode penelitian yang dilakukan adalah metode literature [5], dimana penulis mengumpulkan informasi dari beberapa buku dan jurnal. Pada penelitian ini penulis menekankan pada rancang bangun sistem informasi akuntansi dengan menggunakan database sebagai tempat penyimpanan sistem agar dapat meminimalisir resiko kehilangan data dalam pembuatan laporan keuangan dana subsidi perperiodik.

\section{ALUR ANALISIS PERANCANGAN}

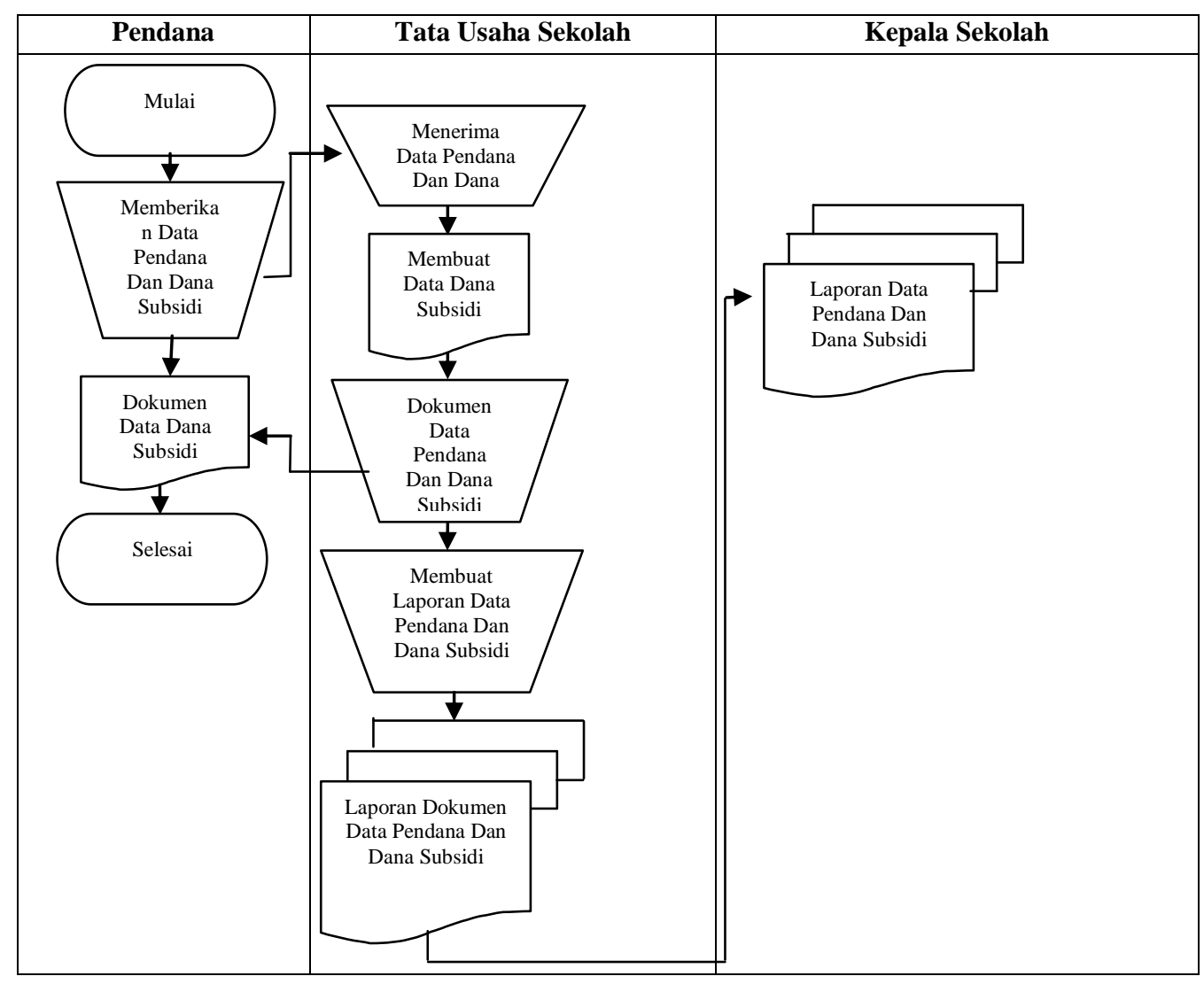

Gambar 1 Alur Perancangan Sistem Informasi Akuntansi Dana Subsidi 


\section{HASIL DAN PEMBAHASAN}

\section{ANALISA PEMBAHASAN}

Dalam penelitian ini terdapat 3 entitas yaitu, Pendana, Tata Usaha dan Kepala Sekolah. Masing-masing entitas berhubungan langsung pada sistem informasi akuntansi untuk meminta kebutuhan yang dibutuhkan pada masing-masing entitas. Pendana akan memberikan data pendana dan data dana subsidi ke Tata Usaha, kemudian Tata Usaha akan memberikan laporan data Pendana dan data dana subsidi ke sistem informasi akuntansi dana subsidi, kemudian mendistribusikan laporan tersebut kepada Kepala Sekolah. Selanjutnya Tata Usaha yang akan memberikan laporan pertanggungjawaban dana subsidi kepada Pendana.

\section{DFD Level 0}

Dalam menggambarkan alur kerja dalam penelitian ini menggunakan Diagram Konteks. Diagram konteks atau DFD level 0 Diagram konteks merupakan gambaran kasar aliran informasi dan data yang akan dilakukan oleh sistem database yang akan dirancang. DFD merupakan detail rancangan dari diagram konteks yang sudah dibuat yang sudah memuat rancangan table database yang akan diimplementasikan pada database yang akan dibuat. Adapun Diagram konteks yang dibuat dalam penelitian ini terlihat pada gambar 2 .

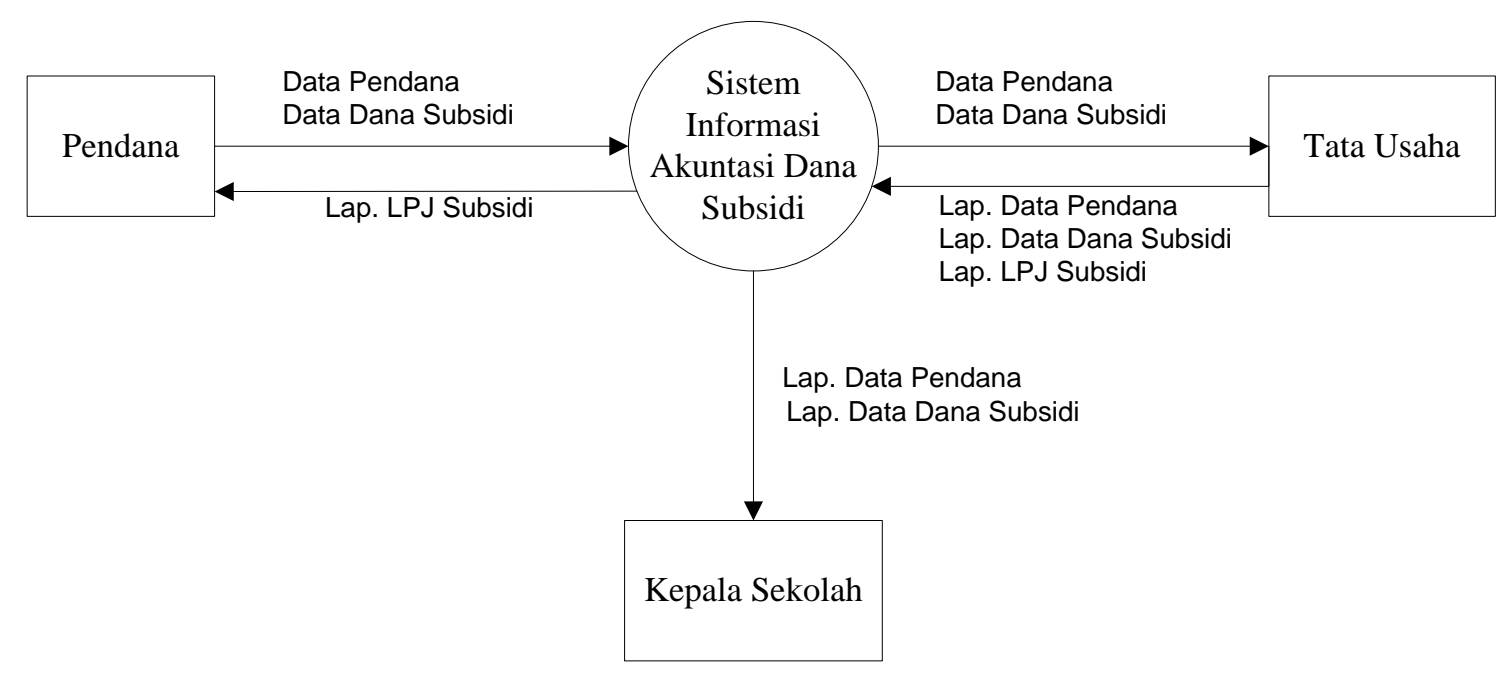

Gambar 2 Rancangan Diagram Konteks Pengolahan Dana Subsidi 
Kemudian penulis membuat turunan dari diagram konteks yaitu DFD level 0 sebagai berikut:

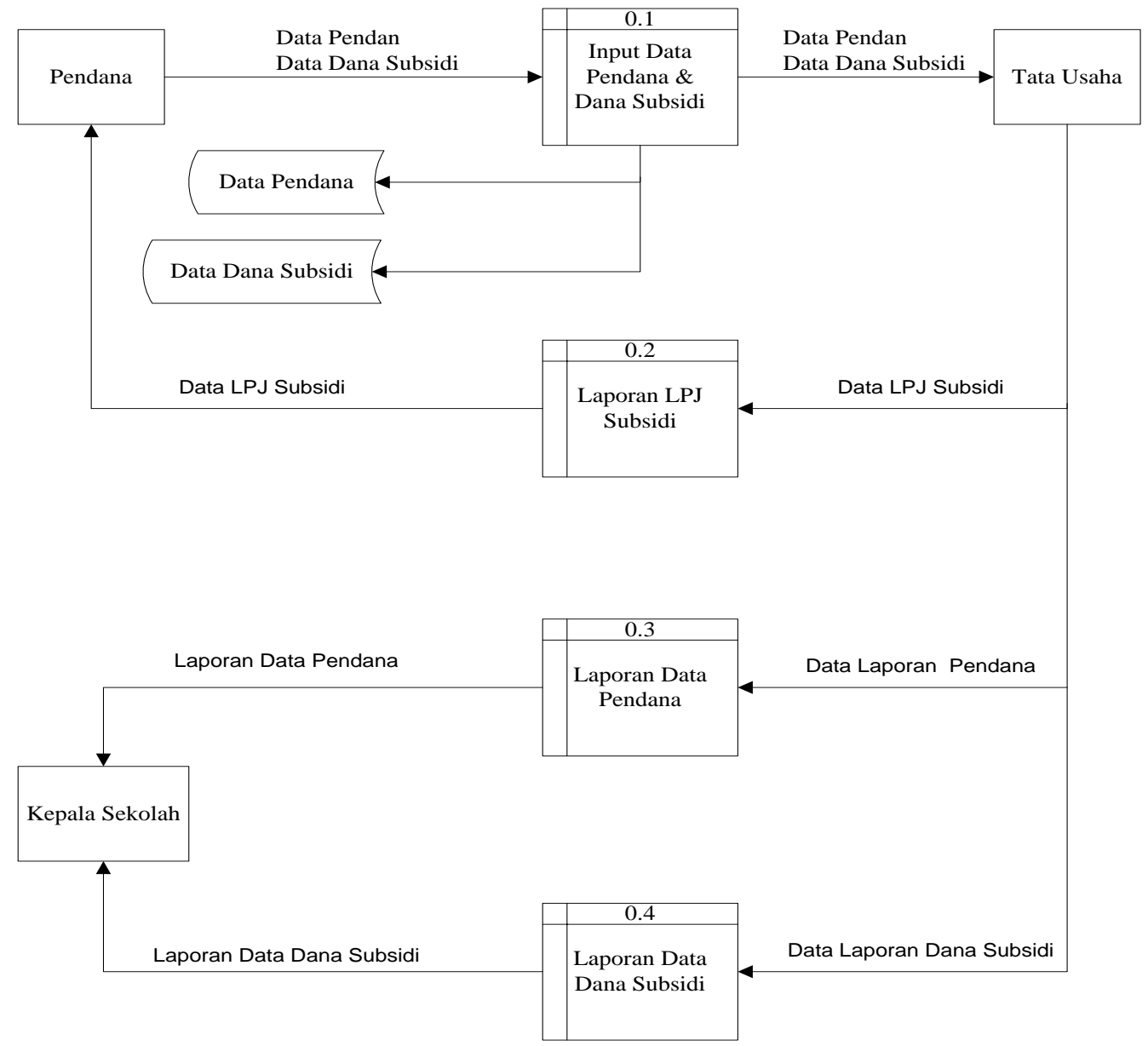

\section{Gambar 3 DFD Level 0 Pengolahan Dana Subsidi}

Dalam perancangan sistem diperlukan suatu model data yang berbentuk diagram yang dapat menjelaskan suatu alur proses sistem yang akan di bangun. Dalam penelitian ini, penulis menggunakan diagram Use Case. Maka digambarlah suatu bentuk diagram Use Case yang dapat dilihat pada Gambar 4: 


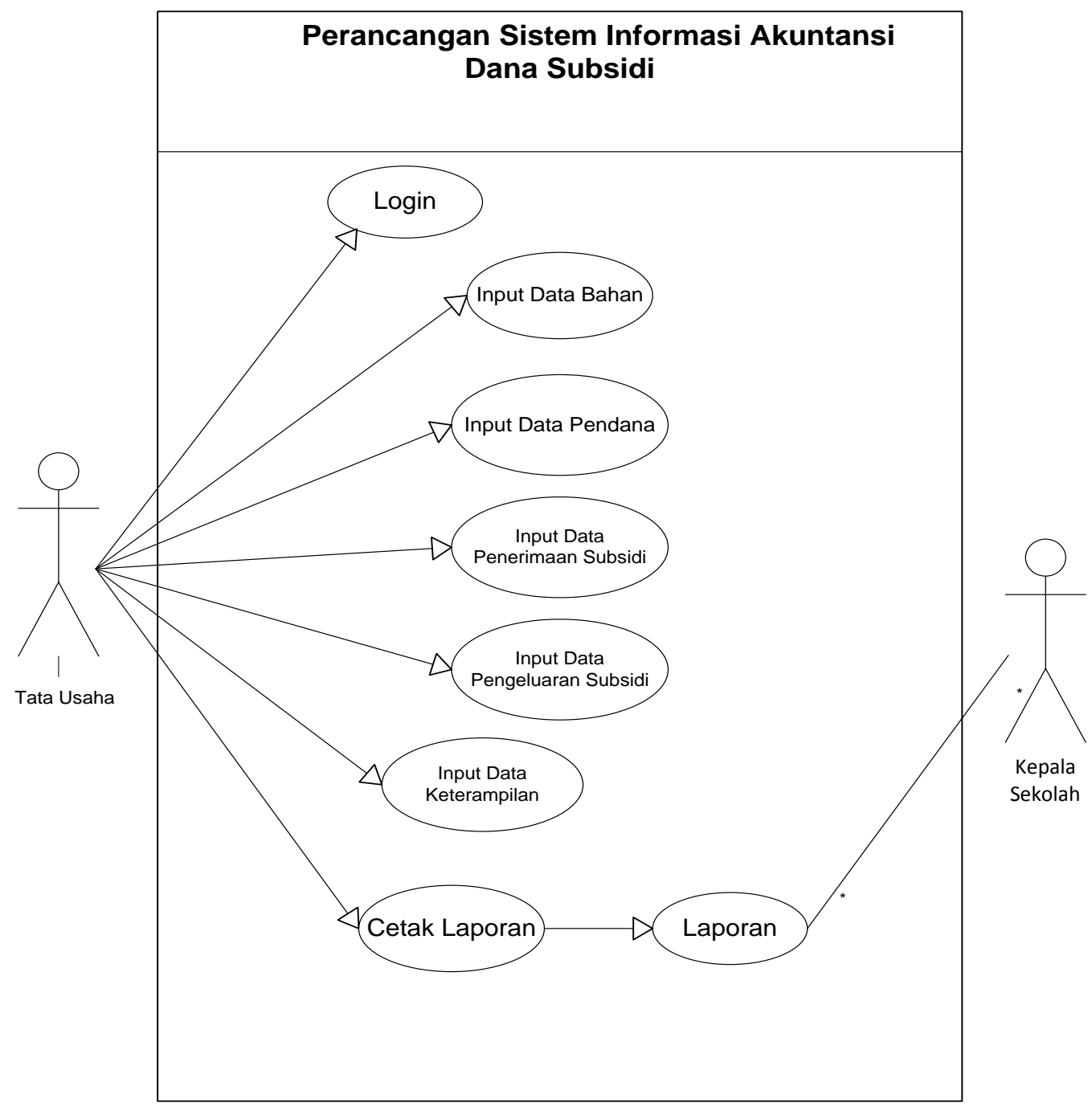

\section{Gambar 4 Diagram Use Case Pengolahan Dana Subsidi}

\section{RELASI TABEL}

Relasi antar tabel adalah hasil dari model entity relationship diagram. Relasi ini akan memperlihatkan rancangan fisik basis data dan juga akan menghasilkan tabel-tabel yang nantinya dapat digunakan dalam proses implementasi sistem. Adapun relasi tabel dalam penelitian ini dapat dilihat dalam gambar 5 : 


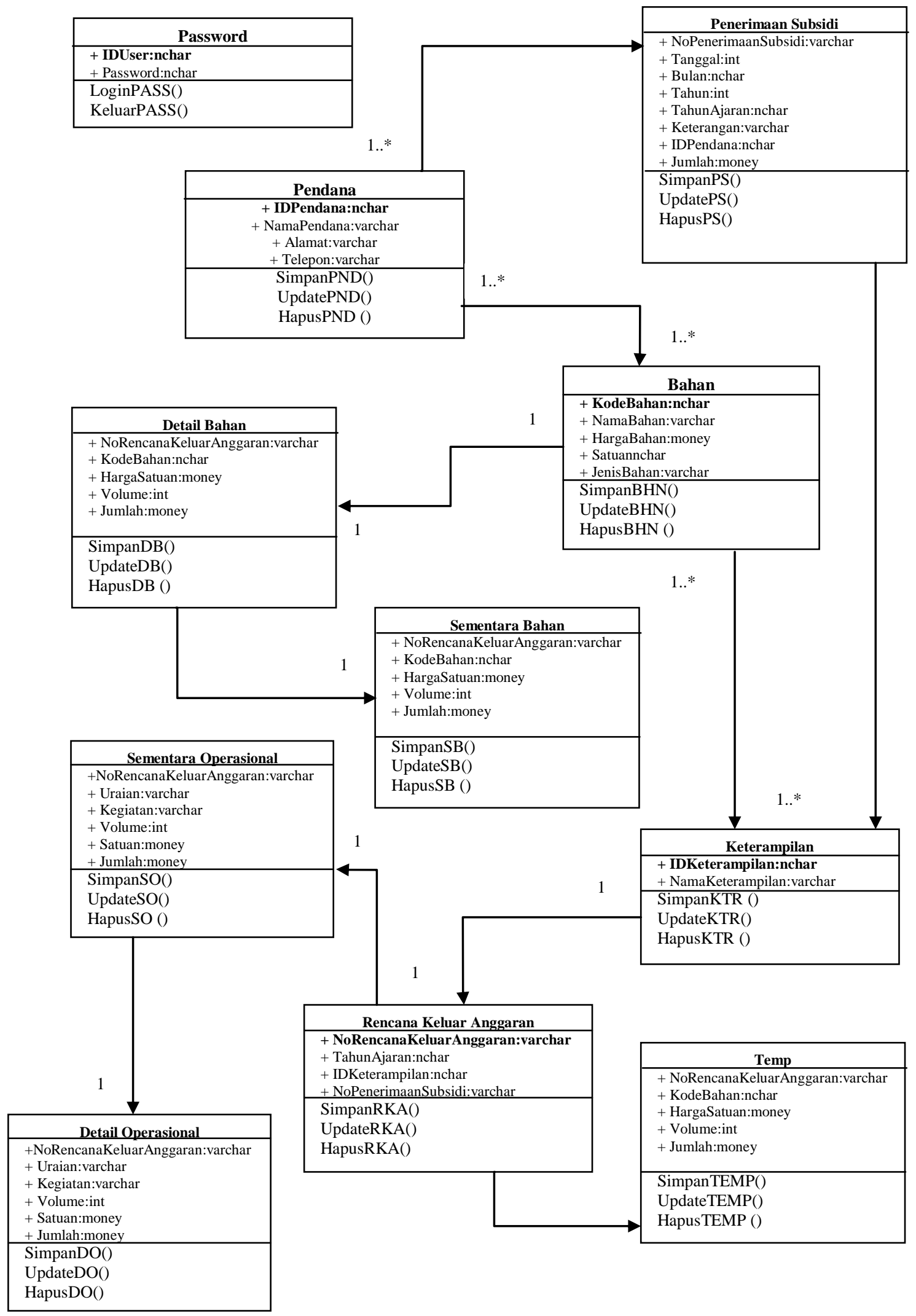

Gambar 5 Relasi Tabel Pengolahan Dana Subsidi 
STRUKTUR DATABASE

Struktur database terdiri dari penjelasan-penjelasan dari tabel yang terdapat pada sistem ini.

TABEL PENDANA

Tabel 1 Struktur Tabel Pendana

\begin{tabular}{|c|c|c|c|}
\hline Nama Field & $\begin{array}{c}\text { Tipe } \\
\text { Data }\end{array}$ & Length & Constraint \\
\hline *ID Pendana & Nchar & $\mathbf{1 0}$ & $\begin{array}{c}\text { Primary Key, Not Null, } \\
\text { update cascade, delete no } \\
\text { action }\end{array}$ \\
\hline Nama Pendana & Varchar & 30 & Not Null \\
\hline Alamat & Varchar & 50 & Not Null \\
\hline Telepon & Varchar & 20 & Not Null \\
\hline
\end{tabular}

TABEL BAHAN

Tabel 2 Struktur Tabel Bahan

\begin{tabular}{|c|c|c|c|}
\hline Nama Field & $\begin{array}{c}\text { Tipe } \\
\text { Data }\end{array}$ & Length & Constraint \\
\hline *Kode Bahan & Nchar & $\mathbf{1 0}$ & $\begin{array}{c}\text { Primary Key, Not Null, update } \\
\text { cascade, delete no action }\end{array}$ \\
\hline Nama Bahan & Varchar & 30 & Not Null \\
\hline Harga Bahan & Money & 8 & Not Null \\
\hline Satuan & Nchar & 10 & Not Null \\
\hline Jenis Bahan & Varchar & 40 & Not Null \\
\hline
\end{tabular}

TABEL KETERAMPILAN

Tabel 3 Struktur TabelKeterampilan

\begin{tabular}{|c|c|c|c|}
\hline Nama Field & $\begin{array}{c}\text { Tipe } \\
\text { Data }\end{array}$ & Length & Constraint \\
\hline *ID Keterampilan & Nchar & $\mathbf{1 0}$ & $\begin{array}{c}\text { Primary Key, Not Null, update } \\
\text { cascade, delete no action }\end{array}$ \\
\hline Nama Keterampilan & Varchar & 30 & Not Null \\
\hline
\end{tabular}

\section{TABEL RENCANA KELUAR ANGGARAN}

Tabel 4 Struktur Tabel Rencana Keluar Anggaran

\begin{tabular}{|c|c|c|c|}
\hline Nama Field & $\begin{array}{c}\text { Tipe } \\
\text { Data }\end{array}$ & Length & Constraint \\
\hline $\begin{array}{c}\text { *No Rencana Keluar } \\
\text { Anggaran }\end{array}$ & Varchar & $\mathbf{2 0}$ & $\begin{array}{c}\text { Primary Key, Not Null, } \\
\text { update cascade, delete no } \\
\text { action }\end{array}$ \\
\hline TahunAjaran & Nchar & 10 & Not Null \\
\hline ID Keterampilan & Nchar & 10 & Foreign Key \\
\hline $\begin{array}{c}\text { No Penerimaan } \\
\text { Subsidi }\end{array}$ & Varchar & 20 & Foreign Key \\
\hline
\end{tabular}


TABEL PENERIMAAN SUBSIDI

Tabel 5 Struktur Tabel Penerimaan Subsidi

\begin{tabular}{|c|c|c|c|}
\hline Nama Field & Tipe Data & Length & Constraint \\
\hline $\begin{array}{c}\text { *No Penerimaan } \\
\text { Subsidi }\end{array}$ & Varchar & $\mathbf{2 0}$ & $\begin{array}{c}\text { Primary Key, Not Null, } \\
\text { update cascade, delete no } \\
\text { action }\end{array}$ \\
\hline Tanggal, Bulan, Tahun & Date & Max & Not Null \\
\hline Tahun Ajaran & Nchar & 10 & Not Null \\
\hline Constraint & Varchar & Max & Not Null \\
\hline ID Pendana & Nchar & 10 & Foreign Key \\
\hline Jumlah & Money & 8 & Not Null \\
\hline
\end{tabular}

TABEL DETAIL BAHAN

Tabel 6 Struktur Tabel Detail Bahan

\begin{tabular}{|c|c|c|c|}
\hline Nama Field & Tipe Data & Length & Constraint \\
\hline $\begin{array}{c}\text { No Rencana Keluar } \\
\text { Anggaran }\end{array}$ & Varchar & $\mathbf{2 0}$ & Foreign Key \\
\hline Kode Bahan & Nchar & 10 & Foreign Key \\
\hline Harga Satuan & Money & 8 & Not Null \\
\hline Volume & Int & 4 & Not Null \\
\hline Jumlah & Money & 8 & Not Null \\
\hline
\end{tabular}

TABEL DETAIL OPERASIONAL

Tabel 7 Struktur Tabel Detail Operasional

\begin{tabular}{|c|c|c|c|}
\hline Nama Field & Tipe Data & $\begin{array}{c}\text { Leng } \\
\text { th }\end{array}$ & Constraint \\
\hline $\begin{array}{c}\text { No Rencana } \\
\text { KeluarAnggaran }\end{array}$ & Varchar & 20 & Foreign Key \\
\hline Uraian & Varchar & Max & Not Null \\
\hline Kegiatan & Varchar & Max & Not Null \\
\hline Volume & Int & 4 & Not Null \\
\hline Satuan & Money & 8 & Not Null \\
\hline Jumlah & Money & 8 & Not Null \\
\hline
\end{tabular}

TABEL TEMP

Tabel 8 Struktur Tabel Temp

\begin{tabular}{|c|c|c|c|}
\hline Nama Field & Tipe Data & Length & Constraint \\
\hline $\begin{array}{c}\text { No Rencana Keluar } \\
\text { Anggaran }\end{array}$ & Varchar & $\mathbf{2 0}$ & Foreign Key \\
\hline Kode Bahan & Nchar & 10 & Foreign Key \\
\hline Harga Satuan & Money & 8 & HargaSatuan \\
\hline Volume & Int & 4 & Volume \\
\hline Jumlah & Money & 8 & Jumlah \\
\hline
\end{tabular}


Pada pembahasan constraint di penelitian ini penulis menggunakan (a)primary key, yaitu kunci utama pada sebuah tabel untuk membatasi pengisian record agar tidak terjadi duplikat, jadi setiap table memiliki primary key masing-masing yang unik. (b)foreign key, atau kunci tamu merupakan penghubung antara satu tabel dengan tabel lainnya, jadi apabila da 2 tabel yang saling berelasi maka harus memiliki foreign key, contohnya pada tabel Rencana Keluar Anggaran. Tabel Rencana Keluar Anggaran memiliki Primary key yaitu NoRencanaKeluarAnggaran, tetapi tabel Rencana Keluar Anggaran memiliki relasi dengan tabel Keterampilan dan tabel Penerimaan Subsidi. Jadi IDKeterampilan dan NoPenerimaanSubsidi merupakan foreign key pada tabel Rencana Keluar Anggaran. (c)check, untuk memberi batasan pada suatu tabel untuk menjamin keakuratan data.pada penelitian ini salah satu tabel yang menggunakan check adalah tabel detail pengiriman, pada jenis pengiriman hanya ada pengiriman via udara, darat atau laut. (d) on update cascade delete no action, untuk menentukan aksi apa yang akan dilakukan pada sebuah baris dalam suatu tabel, pada penelitian ini salah satu tabel yang menggunakan update cascade, delete no action adalah tabel Bahan, pada primary key untuk tabel Bahan menggunakan update cascade, delete no action. Jadi apabila penulis ingin mengupdate IDBahan pada tabel Detail Bahan maka otomatis tabel yang memiliki relasi dengan tabel Detail Bahan seperti tabel Rencana Keluar Anggaran, kebutuhan akan mengupdate IDBahan, kemudian jika kita ingin menghapus IDBahan, yang akan terhapus hanya IDBahan yang ada pada tabel Detail Bahan saja, tabel yang memiliki relasi dengan tabel Detail Bahan tidak akan menghapus IDBahan karena kita menggunakan delete no action.

\section{KESIMPULAN}

Dari hasil penelitian ini, maka dapat ditarik suatu kesimpulan antara lain:

1. Dengan adanya sistem informasi akuntansi dana subsidi, pengolahan data dana subsidi dapat diproses perperiodik.

2. Dengan adanya analisa sistem dapat mengidentifikasi masalah atau hambatan yang terjadi dan kebutuhan yang diharapkan sehingga muncul perbaikan sistem.

3. Sistem ini mempermudah user untuk menampilkan data pendana, data bahan, data penerimaan dan pengeluaran subsidi serta laporan pengolahan dana subsidi.

4. Dengan Menggunakan Constraint dapat lebih menjamin keakuratan data.

5. Sistem yang dirancang telah digambarkan dalam DFD level 0.

\section{SARAN}

Saran yang diharapkan untuk mengembangkan sistem ini adalah :

1. Sistem ini harus terintegrasi dengan sistem terkait sehingga menjadi open source dikalangan user.

2. Sistem ini sebaiknya dilengkapi dengan data laporan, sehingga setiap proses yang dilakukan terdokumentasi secara akurat.

3. Diperlukan tenaga ahli dalam menggunakan sistem untuk menjaga dan memelihara sistem agar dapat berjalan dengan baik.

\section{DAFTAR PUSTAKA}

[1] Sutabri, Tata. 2005.Sistem Informasi Manajemen. Andi : Yogyakarta.

[2] Anggadini, Dewi Sri. 2012. Sistem Informasi Akuntansi. Graha Ilmu:Jakarta.

[3] Istianingsih dan Setyo Hari Wijanto.2008.Pengaruh Kualitas Sistem Informasi, Kualitan Informasi, dan Percived Usefulness Terhadap Kepuasan Pengguna Software Akuntansi. Simposium Nasional Akuntansi IX, Pontianak.

[4] Sugiyono. 2013. Metode Penelitian Kuantitatif, Kualitatif, dan R \& D. Bandung : Alfabeta. 